\title{
Multi-Element Determination of Trace Elements in Natural Water Reference Materials by ICP-SFMS after Tm Addition and Iron Co-precipitation
}

\author{
Germain Bayon ${ }^{1,{ }^{*}}$, Dominique Birot ${ }^{1}$, Claire Bollinger ${ }^{2,3}$, Jean Alix Barrat ${ }^{2,3}$ \\ ${ }^{1}$ Département Géosciences Marines, IFREMER, 29280 Plouzané, France \\ 2 Université Européenne de Bretagne, 35000 Rennes, France \\ ${ }^{3}$ IUEM, CNRS UMR6538, Université de Brest, 29280 Plouzané, France \\ *: Corresponding author : Germain Bayon, email address : gbayon@ifremer.fr
}

\begin{abstract}
:
We report on an improved method for determining trace element abundances in seawater and other natural waters. The analytical procedure involves co-precipitation on iron hydroxides after addition of a Tm spike, and measurement by inductively coupled plasma-sector field mass spectrometry (ICP-SFMS). The validity of the method was assessed through a series of co-precipitation experiments, using ultra-diluted solutions of a certified rock reference material (BIR-1). Results obtained for four natural water reference materials (NASS-5, CASS-4, SLEW-3, SLRS-4) are in agreement with published working values for rare earth elements, yttrium, vanadium and, when available, for hafnium, zirconium, thorium and scandium. A set of proposed values with uncertainties typically better than $8 \% \mathrm{RSD}$ is proposed for $\mathrm{Hf}, \mathrm{Zr}$ and $\mathrm{Th}$.
\end{abstract}

\section{Résumé :}

Nous présentons une méthode révisée pour la détermination des teneurs en éléments traces dans l'eau de mer et autres eaux naturelles. Notre procédure analytique implique la co-précipitation sur des hydroxydes de Fer, après ajout d'un spike de Tm, et la mesure par spectrométrie de masse à secteur magnétique couplée à une source à plasma induit (ICP-SFMS). La validité de la méthode a été testée en réalisant une série d'expérimentations de co-précipitation, à l'aide de solutions ultra-diluées d'un matériau de référence géologique certifié (BIR-1). Les résultats obtenus pour quatre matériaux de références d'eaux naturelles (NASS-5, CASS-4, SLEW-3, SLRS-4) sont en accord avec les valeurs de travail publiées dans la littérature pour les Terres Rares, Yttrium, Vanadium et, lorsqu'elles sont présentes, pour Hafnium, Zirconium, Thorium et Scandium. Des valeurs de référence avec des incertitudes inférieures à $8 \% \mathrm{CV}$ sont proposées pour $\mathrm{Hf}$, Zr et Th.

Keywords : seawater ; reference material ; ICP-MS ; trace elements ; rare earth elements

Mots clés : eau de mer ; matériau de référence ; ICP-MS ; éléments traces ; Terres Rares 


\section{Introduction}

Trace elements are key tracers for identifying the source of elements in seawater and for understanding marine biogeochemical processes (e.g. Bruland and Lohan, 2003). Over the last decades, the advent of analytical techniques have enabled marine geochemists to determine seawater concentrations of most elements in the periodic table, including those occurring at very low concentrations, at the $0.1 \mathrm{ng} \mathrm{l}-1$ level. A number of analytical procedures have been successfully developed for measuring dissolved trace metal abundances in the ocean, using various pre-concentration procedures prior to analysis. The most common methods used to pre-concentrate trace elements include liquid-liquid extraction (e.g. Shabani et al., 1990; Aggarwal et al., 1996; Bau and Dulski, 1996), ion exchange resins (e.g. Esser et al., 1994; Yabutani et al., 2001; Zhu et al., 2005), and coprecipitation onto oxides (e.g. Akagi et al., 1985; Greaves et al., 1989; Shaw et al., 2003) or other mineral phases (e.g. Grindberg et al., 2005). Isotope dilution (ID) mass spectrometry has usually been the method of choice for determining trace element concentrations in the ocean with low measurement uncertainty (e.g. Greaves et al., 1989; Wu and Boyle, 1997; McKelvey and Orians, 1998; Shaw et al., 2003). Inductively coupled plasma mass spectrometry (ICP-MS) methods, without the ID technique, have also proved to be highly reliable for determining dissolved element traces in seawater, and to be particularly wellsuited for routine measurements (e.g. Shabani et al., 1990; Möller et al., 1992; Rodushkin and Ruth, 1997; Willie and Sturgeon, 2001). The validation of these 
ICP-MS methods is crucially dependent upon the analysis of well-characterized certified reference materials (CRMs). To date, however, many trace elements in seawater (e.g. Hf, Zr, Th, Sc) are still not well characterized in the natural water CRMs commonly used for procedure validation.

Here, we report on an improved method for the determination of several trace metals in

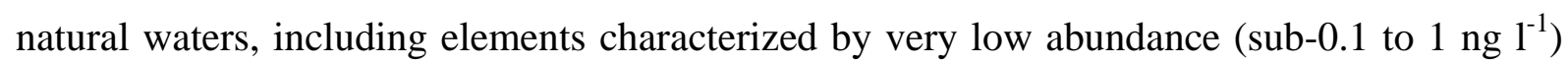
in the ocean, such as REEs, Hf, Th and Sc. Our method is based on the procedure developed recently by Bayon et al. (2009), and applied successfully to a wide range of geological samples. It involves addition of a Tm spike and pre-concentration using iron co-precipitation, prior to analysis by ICP-SFMS. The addition of a small amount of Tm to the sample produces a positive Tm anomaly in the resulting REE pattern, which allows calculation of precise trace element concentrations.

\section{Experimental}

\section{Reagents and materials}

Ultra-pure Milli-Q (18.2 M $\Omega \mathrm{cm}$ ) Millipore ${ }^{\circledR}$ water was used throughout the course of our experiments, together with nitric and hydrochloric acid solutions (commercial grade, Merck) purified twice using a sub-boiling system, and ultra-pure hydrofluoric acid solution (HIPERPUR-PLUS ${ }^{\circledR}$, Panreac). High-quality ammonia solution ( 25\%, ARISTAR ${ }^{\circledR}$, VWR BDH Prolabo), and Fe (10,000 $\mu \mathrm{g} \mathrm{ml}^{-1}$, Specpure ${ }^{\circledR}$ ) and Tm (custom-grade, CGTM1-1, Inorganic Ventures inc.) standard solutions were used for co-precipitation. The Fe solution was taken up in $4 \mathrm{~mol} \mathrm{l}^{-1} \mathrm{HCl}$, and loaded onto a column filled with cation-exchange AG 50W-X8 resin (Bio-Rad Laboratories). This purification step led to significantly improved blanks for La and Ce, which were both retained on the AG 50W-X8 resin. All polypropylene Nalgene ${ }^{\circledR}$ bottles and Savillex ${ }^{\circledR}$ jars used in this study were pre-cleaned thoroughly with mixed nitric (10\% v/v) and HF (1\% v/v) solutions before use.

Four CRMs purchased from the National Research Council of Canada (NRCC) were analysed to validate our procedure: CASS-4 (nearshore seawater); NASS-5 (seawater), SLEW-3 (estuarine water), and SLRS-4 (river water). These reference materials are certified for a 
wide range of trace elements (e.g. As, Cd, Cr, Co, Cu, Fe, Pb, Mn, Mo, Ni, U, V, Zn), and are now relatively well characterized for the REEs (e.g. Lawrence and Kamber, 2007). To the best of our knowledge, however, there are no or only few published data for $\mathrm{Hf}$, Zr, Th and Sc concentrations in these natural water CRMs. One well-characterized rock reference material (basalt BIR-1, United States Geological Survey, USGS) was also used for co-precipitation experiments. External calibration and correction for instrumental drift was performed using the basalt reference material BHVO-2 (USGS).

\section{Co-precipitation experiments}

A series of co-precipitation experiments was conducted in order to determine the best suited procedure. Experiments were made using an ultra-diluted solution ( $\sim$ X 2,500,000) of the rock reference material BIR-1. About $50 \mathrm{mg}$ of BIR-1 powder were weighed carefully, digested on a hotplate $\left(24 \mathrm{~h}\right.$ at $\left.130^{\circ} \mathrm{C}\right)$ with a mixed (3:1) concentrated $\mathrm{HF}$ and $\mathrm{HCl}$ solution, then dried down and taken up in $6 \mathrm{~mol} \mathrm{l}^{-1} \mathrm{HCl}$. An aliquot of the 'mother solution' was then weighed carefully, dried down and diluted accordingly to produce a 2-L weakly-acidified solution ( $\mathrm{pH} \approx 1$ ) with seawater-like trace metal concentrations (i.e. around $1 \mathrm{ng} \mathrm{l}^{-1}$ ). Four series of four $100 \mathrm{ml}$ aliquots of that ultra-diluted BIR-1 solution were then processed for the co-precipitation experiments under different conditions, for temperature and total duration ranging from $\sim 20^{\circ} \mathrm{C}$ to $140^{\circ} \mathrm{C}$ and from three hours to five days, respectively: 1) coprecipitation at room temperature during $36 \mathrm{~h} ; 2$ ) five-day co-precipitation at room temperature; 3) five-day co-precipitation in an oven at $70^{\circ} \mathrm{C}$; and 4) three-hour coprecipitation on a hotplate at $140^{\circ} \mathrm{C}$.

\section{Procedure}

One hundred $\mathrm{ml}$ of natural water CRM (or ultra-diluted BIR-1 solution) were transferred into an acid-cleaned $125 \mathrm{ml}$ Nalgene HDPE bottle (for the experiments conducted at room temperature or in the oven at $70^{\circ} \mathrm{C}$ ), or a $125 \mathrm{ml}$ Savillex PFA jar (for the experiments performed on hotplate), and weighed. About $1 \mathrm{ng}$ of Tm (in solution) was then added to the bottle (or jar), and weighed carefully. About $600 \mu \mathrm{l}$ of our purified Fe solution was also added to the bottle (or jar). After shaking thoroughly the bottle (or jar), ammonia solution was added drop wise, with occasional stirring, until Fe-hydroxide precipitation occurs (i.e. appearance of an orange color at $\mathrm{pH} \sim 8-8.5$ ).

After completion of the experiment, the solution was rinsed into a pre-cleaned centrifuge tube and centrifuged for $3 \mathrm{~min}$ at $3000 \mathrm{rpm}$. The clear supernatant was decanted and the centrifuge 
tube was filled with $40 \mathrm{ml}$ of ultra-pure water, stirred, and then centrifuged again. The same procedure was repeated once more in order to wash completely the iron hydroxides. The Fe hydroxides were then dissolved in $6 \mathrm{M} \mathrm{HCl}$, dried down on hotplate, taken up in $300 \mu \mathrm{l} 3 \mathrm{M}$ $\mathrm{HNO}_{3}$, and diluted to $3 \mathrm{ml}$ ultra-pure water prior to measurement by ICP-SFMS.

\section{Instrumentation and analysis}

The measurements were made at the Pôle Spectrometrie Océan (PSO), Brest. The instrument used was a ELEMENT 2 ICP-SFMS (Thermo Scientific, Bremen, Germany), equipped with an ASX 100 autosampler (CETAC Technologies, Omaha, NE, USA). The ELEMENT2 was operated in low (LRM, $\mathrm{m} / \Delta \mathrm{m}$ approx. 300) and medium (MRM, $\mathrm{m} / \Delta \mathrm{m}=4500)$ resolution modes, depending on the required sensitivity and potential interferences for each element. The instrumental operating conditions and measuring parameters are given in Table 1 . The REEs were analysed with the low resolution mode to enhance sensitivity, but were corrected for interferences, following the procedure of Bayon et al. (2009).

Elemental concentrations in the studied samples were calculated using the Tm addition method (Barrat et al., 1996). The addition of a small amount of Tm to the sample produces a positive Tm anomaly in the resulting REE pattern, which allows calculation of precise trace element concentrations. Details on the calculations can be found in Bayon et al. (2009). Briefly, the raw data were calibrated against an unspiked (no added Tm) BHVO-2 reference solution (diluted $~ 10,000$ times), run after every three samples in order to correct for the instrumental drift. The BHVO-2 values used for the calculations (Barrat et al., 2007) are given in Table 1. Elemental abundances in the sample analysed are then calculated using the mass of sample spiked with Tm and the amount of Tm added. Polyatomic oxide and hydroxide interferences were corrected using oxide formation rates determined by analysing solutions of ultra-pure water, $\mathrm{Ba}+\mathrm{Ce}, \mathrm{Pr}+\mathrm{Nd}$ and $\mathrm{Sm}+\mathrm{Eu}+\mathrm{Gd}+\mathrm{Tb}$ at the beginning of the measurement cycle (Bayon et al., 2009). Oxide formation rates during the course of this study were generally $\sim 0.1 \%$ for $\mathrm{BaO}+/ \mathrm{Ba}+,<0.1 \%$ for $\mathrm{CeOH}+/ \mathrm{Ce}+$ and $\sim 3 \%$ for $\mathrm{PrO}+/ \mathrm{Pr}+$. Barium oxide interference on the ${ }^{151}$ Eu signal averaged $\sim 7 \%$ for SLRS-4, $~ 10 \%$ for NASS-5, $\sim 15 \%$ for CASS-4, and $~ 35 \%$ for SLEW-3. Cerium hydroxide and Pr oxide interferences on the ${ }^{157} \mathrm{Gd}$ signal were significant, ranging from $12 \%$ for SLEW-3 to $30 \%$ for SLRS-4. The

${ }^{143} \mathrm{Nd}$ oxide interference on ${ }^{159} \mathrm{~Tb}$ was also significant, from $\sim 6 \%$ (SLEW-3) to $\sim 16 \%$ (SLRS4). Oxide and hydroxide interference corrections for all other REE were negligible. 


\section{Results and discussion}

\section{Iron co-precipitation}

Results of the co-precipitation tests are shown in Fig. 1, expressed as the mean deviation of our measurements relative the ultra-diluted BIR-1 solution used for the experiments. The BIR-1 concentrations (Jochum et al., 2005) and associated uncertainties (1 standard deviation) used for calculations are given in Table 2. For a large number of elements (Y, Ce, Pr, Nd, Sm, Eu, Gd, Tb, Dy, Ho, Er, Yb, Lu, Hf, Sc, V), mean concentrations agree well, within error, with those calculated for our ultra-diluted BIR-1 solution. For these elements, changing either the experimental temperature or the duration of the experiment had no measurable effect on the co-precipitation efficiency. For all other elements analysed in this study (Zr, $\mathrm{Ba}, \mathrm{La}, \mathrm{Th}, \mathrm{U}, \mathrm{Mn}, \mathrm{Ni}$ and $\mathrm{Cu}$ ), the efficiency of the co-precipitation was improved at high temperatures. Reliable concentrations for $\mathrm{Th}$ and $\mathrm{Ni}$ were obtained after experiments conducted in the oven $\left(70^{\circ} \mathrm{C}\right)$ or on hotplate $\left(140^{\circ} \mathrm{C}\right)$, whereas accurate concentrations for $\mathrm{La}$ and $\mathrm{U}$ were only measured when co-precipitation had taken place on hotplate. Uranium coprecipitation exhibited very poor intermediate precision (intralaboratory precision), however, suggesting that factors other than temperature and time played a role in the co-precipitation efficiency (e.g. pH). In any case, the mean deviation of our experiments remained poor for both $\mathrm{Ba}$ and $\mathrm{Cu}$, even at high temperature (i.e. $-42 \%$ for $\mathrm{Ba},-17 \%$ for $\mathrm{Cu}$ ), clearly indicating that those two elements were not scavenged efficiently onto Fe-hydroxides during coprecipitation. Interestingly, this shows that iron co-precipitation can provide an effective mean for separating Ba from REEs, hence leading practically to a much reduced interference of ${ }^{135} \mathrm{BaO}$ on the ${ }^{151} \mathrm{Eu}$ peak during analysis. From the results of the experimental analysis described above, the co-precipitation procedure adopted was the one taking place on hotplate at high-temperature $\left(140^{\circ} \mathrm{C}\right)$.

\section{Procedural blanks}

Procedural blanks were prepared using the same method as for water samples (Table 2). For most elements listed in Table 2, average blanks are the same throughout, but their contributions to total signal intensities are much lower for SLRS-4 (always below 1\%, with the exception of Ni: 14\%), than for the other natural water CRMs. For the seawater and estuarine water CRMs (CASS-4, NASS-5, SLEW-3), average blank contributions were 
always below 2\% for REEs, Y, Ba, U and V, and below 10\% for Zr and Hf. Total blank contributions for Th range from 7\% (CASS-4), 17\% (SLEW-3), to $24 \%$ (NASS-5). Blank contributions can even be higher for Sc (up to $>100 \%$ in NASS-5), Mn (up to $54 \%$ in NASS5), $\mathrm{Ni}$ (up to $32 \%$ in NASS-5), and Cu (up to $28 \%$ in NASS-5). Clearly, the presence of high blank levels for these last four elements prevents their accurate determination in seawater using our procedure. Further improvement in the cleaning process of the Fe solution, using ion exchange resins, would be required to assess whether $\mathrm{Mn}, \mathrm{Ni}, \mathrm{Cu}$ and, to a lesser extent, Sc can be measured accurately and precisely by ICP-SFMS after iron co-precipitation and Tm addition.

\section{Natural water reference materials}

The analytical results for the natural water CRMs are summarized in Table 3 and Table 4, together with selected literature data, with uncertainties given as 2 standard deviations (2s) of the set of our replicate measurements, providing an estimate of intermediate precisions. The precision on our series of replicate measurements ( $\mathrm{n}=3$ for SLRS-4, CASS-4 and SLEW-3; $n$ $=5$ for NASS-5) is also expressed as the relative standard deviation (RSD). Elements that were successfully determined during our co-precipitation experiments are listed in Table 3 and Table 4 and discussed below.

Vanadium: Vanadium concentrations are well-characterized in seawater and, with the exception of NASS-5, are certified in the CRMs analysed in this study. Our measured V concentrations agree within 10\% with these certified/preferred values: $1.28 \pm 0.02 \mu \mathrm{g} \mathrm{l}^{-1}$ for CASS-4 (certified value: $1.18 \pm 0.16 \mu \mathrm{g} \mathrm{l}^{-1}$ ); $0.35 \pm 0.02 \mu \mathrm{L}$-1 for SLRS-4 (certified value: $0.32 \pm 0.03 \mu \mathrm{g} \mathrm{l}^{-1}$ ); $2.58 \pm 0.15 \mu \mathrm{g} \mathrm{l^{-1 }}$ for SLEW-3 (certified value: $2.57 \pm 0.31 \mu \mathrm{g} \mathrm{l}^{-1}$ ), and $1.33 \pm 0.03 \mu \mathrm{g} \mathrm{l}^{-1}$ for NASS-5 (preferred value: $1.28 \pm 0.12 \mu \mathrm{g} \mathrm{l}^{-1}$; Jochum et al., 2005). Precision (RSD) for $\mathrm{V}$ is better than $3 \%$.

Rare earth elements and Yttrium: Post-Archean Australian shales (PAAS)-normalized (Taylor and McClennan, 1985) REE patterns for the four natural water CRMs analysed are shown in Fig. 2. The accuracy of our procedure can be assessed by comparing our results to recently published high quality reference values (e.g. Shaw et al., 2003; Rodushkin et al., 2005; Zhu et al., 2005; Lawrence and Kamber, 2007; Rahmi et al., 2007). With few exceptions, our data are in agreement with those reported in these studies. Our Heavy REE data for CASS-4 and SLEW-3 are slightly lower (e.g. 26\% for Lu and 20\% for Yb) than those 
from Lawrence and Kamber (2007), but very similar to those from Zhu et al. (2005). In addition, our Eu mean value for SLRS-4 is slightly higher ( 15\%) than those reported in other studies, which may indicate an undercorrection of the $\mathrm{BaO}+$ interference. Precision for the REEs and Y is always below 5\% RSD. Note that the Sm anomaly observed in Fig. 2 for each of the four CRMs analysed does not correspond to a natural oceanic or riverine feature. As discussed previously (see Lawrence and Kamber, 2007), these Sm anomalies were attributed to selective contamination during preparation of the reference materials.

Hafnium: Two Hf values have been reported for SLRS-4 (3.3 $\pm 0.6 \mathrm{ng} \mathrm{l}^{-1}$; Rodushkin et al., 2005), and NASS-5 (0.22 $\pm 0.04 \mathrm{ng} \mathrm{l}^{-1}$; Firdaus et al., 2007) following pre-concentration using solid-phase extraction on TSK-8-hydroxyquinoline resin. Our results for SLRS-4 (3.01 $\left.\pm 0.03 \mathrm{ng} \mathrm{l}^{-1}\right)$ and NASS-5 $\left(0.17 \pm 0.02 \mathrm{ng} \mathrm{l}^{-1}\right)$ are in agreement with these published data, within $\sim 9$ and 23\%, respectively. For CASS-4 and SLEW-3, our mean Hf concentrations are $0.35 \pm 0.03 \mathrm{ng} \mathrm{l}^{-1}$ and $0.19 \pm 0.02 \mathrm{ng} \mathrm{l}^{-1}$, respectively. Relative standard deviations for Hf vary from $\sim 0.6 \%$ for SLRS-4 to $\sim 7 \%$ for NASS-5.

Zirconium: Our Zr mean value for NASS-5 (15.4 $\pm 0.9 \mathrm{ng} \mathrm{l}^{-1}$ ) agrees well (within 6\%) with that given by Firdaus et al. (2007): $16.4 \pm 0.8 \mathrm{ng} \mathrm{l}^{-1}$. However, our measured value for SLRS$4\left(93 \pm 3 \mathrm{ng} \mathrm{l}^{-1}\right)$ is slightly lower than the preferred value $\left(120 \pm 15 \mathrm{ng} \mathrm{l}^{-1}\right.$; Jochum et al., 2005) and that reported by Rodushkin et al. (2005): $106 \pm 4 \mathrm{ng} \mathrm{l}^{-1}$. To the best of our knowledge, there are also no published data for Zr in CASS-4 and SLEW-3, for which we have determined the following concentrations: $25.3 \pm 0.4 \mathrm{ng} \mathrm{l}^{-1}$ and $11 \pm 2 \mathrm{ng} \mathrm{l}^{-1}$, respectively. The precision on our measured $\mathrm{Zr}$ values range from 1\% RSD for CASS-4 to 8\% RSD for SLEW-3.

Thorium: Results for Th in SLRS-4 (21.5 $\left.\pm 0.9 \mathrm{ng} \mathrm{l}^{-1}\right)$ and CASS-4 $\left(0.51 \pm 0.02 \mathrm{ng} \mathrm{l}^{-1}\right)$ agree within $\sim 20 \%$ with published values: $18 \pm 3 \mathrm{ng} \mathrm{l}^{-1}$ (compiled, Yeghicheyan et al., 2001) and $17 \pm 2 \mathrm{ng} \mathrm{l}^{-1}$ (Rodushkin et al., 2005) for SLRS-4; $0.5 \pm 0.1 \mathrm{ng} \mathrm{l}^{-1}$ (Grindberg et al., 2005) and $0.46 \pm 0.02 \mathrm{ng} \mathrm{l}^{-1}$ (Zhu et al., 2005). The concentration obtained for NASS-5 (0.17 $\pm 0.02 \mathrm{ng}$ $\mathrm{l}^{-1}$ ) agrees with the work of Zhu and co-workers $\left(<0.3 \mathrm{ng} \mathrm{l}^{-1}\right)$, but differs markedly from the value proposed by Grindberg et al.(0.6 $\left.\pm 0.1 \mathrm{ng} \mathrm{l}^{-1}\right)$. Similarly, our Th value for SLEW-3 $\left(0.22 \pm 0.02 \mathrm{ng} \mathrm{l}^{-1}\right)$ disagrees with that given by Grindberg et al. $\left(1.2 \pm 0.2 \mathrm{ng} \mathrm{l}^{-1}\right)$. Unfortunately, there are no other Th reference data available for comparison, and additional 
work will be needed to better constrain the Th concentration in these last two CRMs. With the exception of NASS-5 ( 7\%), our relative standard deviations for Th are below 3\%.

Scandium: There are only few published data for Sc in natural water CRMs: $11.3 \pm 0.6 \mathrm{ng} \mathrm{l}^{-1}$ (Krachler et al., 2004), $12 \pm 1 \mathrm{ng} \mathrm{l}^{-1}$ (Rodushkin et al., 2005), both for SLRS-4. Our measured Sc concentration for SLRS-4 (11.1 $\left.\pm 0.9 \mathrm{ng} \mathrm{l}^{-1}\right)$ agrees well (within $\left.~ 8 \%\right)$ with the data above, with a relative standard deviation better than 5\%. Note that another, much higher, Sc value (52 $\pm 3 \mathrm{ng} \mathrm{l}^{-1}$ ) was also proposed for SLRS-4 (Lukman et al., 2007), but it was obtained using ICP atomic emission spectroscopy. Our proposed values for SLEW-3, CASS-4 and NASS-5 are $0.55 \pm 0.09 \mathrm{ng} \mathrm{l}^{-1}$ (8\% RSD), $0.08 \pm 0.06 \mathrm{ng} \mathrm{l}^{-1}$ (38\% RSD), and $<0.08 \mathrm{ng} \mathrm{l}^{-1}$, respectively.

\section{Summary}

An improved procedure was developed for the determination of trace element concentrations in seawater and other natural waters. The procedure involved addition of a Tm spike to 100 ml water samples, prior to a pre-concentration step using co-precipitation onto Fe-hydroxides, and measurement by ICP-SFMS. A series of experiments showed that the efficiency of coprecipitation is much improved for a number of trace elements when performed at high temperature $\left(140^{\circ} \mathrm{C}\right)$ on hotplate. Results obtained in this study for a series of natural water CRMs (CASS-4, NASS-5, SLEW-3, SLRS-4) were, to a large extent, in agreement with literature data for the following elements: V, REEs, Y, Zr, Hf, Th, and Sc. The relative standard deviation was typically below $5 \%$ for $\mathrm{V}$, REEs and $\mathrm{Y}$, and better than $10 \%$ for $\mathrm{Hf}, \mathrm{Zr}$ and Th. The determination of Sc concentration in the seawater CRMs (CASS-4 and NASS-5) was complicated by the presence of large blank contributions, and would require further development. Compared to other published methods, this procedure is relatively straightforward. It also allows simultaneous determination of several key elements (e.g. REEs, Hf, Zr, Th) that are particularly important in the study of marine biogeochemical processes, and hence should be particularly attractive as a routine method for future studies. 


\section{Acknowledgement}

This study was funded through the ERIG-3D project (IFREMER and TOTAL). J. Etoubleau is thanked for discussion and helpful comments. Thomas Meisel (Editor) and three anonymous reviewers are acknowledged for providing thoughtful and detailed reviews.

\section{References}

Aggarwal J.K., Shabani M.B., Palmer M.R. and Ragnarsdottir K.V. (1996)

Determination of the rare earth elements in aqueous samples at sub-ppt levels by inductively coupled plasma mass spectrometry and flow injection ICPMS. Analytical Chemistry, 68, 4418-4423

Akagi T., Fuwa K. and Haraguchi H. (1985)

Simultaneous multi-element determination of trace metals in sea water by inductively-coupled plasma atomic emission spectrometry after coprecipitation with gallium. Analytica Chimica Acta, 177, 139-151.

Barrat J.A., Keller F., Amossé J., Taylor R.N., Nesbitt R.W. and Hirata T. (1996)

Determination of rare earth element in sixteen silicate reference samples by ICP-MS after Tm addition and ion exchange separation. Geostandards Newsletter, 20, 133-139.

Barrat J.A., Yamaguchi A., Greenwood R.C., Bohn M., Cotten J., Benoit M. and Franchi I.A. (2007)

The Stannern trend eucrites: Contamination of main group eucritic magmas by crustal partial melts. Geochimica Cosmochimica Acta, 71, 4108-4124.

Bau M., Dulski P. (1996)

Anthropogenic origin of positive gadolinium anomalies in river waters. Earth and Planetary

Science Letters, 143, 245-255

Bayon G., Barrat J.A., Etoubleau J., Benoit M., Révillon S. and Bollinger C. (2009) 
Determination of rare earth elements, Sc, Y, Zr, Ba, Hf and Th in geological samples by ICPMS after Tm addition and alkaline fusion. Geostandards and Geoanalytical Research, 32, 51-62.

Bruland K.W. and Lohan M.C. (2003)

Controls of trace metals in seawater. In: Elderfield H., Holland H.D. and Turekian K.K. (eds), Treatise on geochemistry. The Oceans and Marine Geochemistry vol. 6. Elsevier/Pergamon Press (London), 23-48.

Esser B.K., Volpe A., Kenneally J.M. and Smith D.K. (1994)

Preconcentration and Purification of Rare Earth Elements in Natural Waters Using SilicaImmobilized 8-Hydroxyquinoline and a Supported Organophosphorus Extractant. Analytical Chemistry, 66, 1736-1742.

Firdaus M.L., Norisuye K., Sato T., Urushihara S., Nakagawa Y., Umetani S. and Sohrin Y. (2007)

Preconcentration of Zr, Hf, Nb, Ta and W in seawater using solid-phase extraction on TSK-8hydroxyquinoline resin and determination by inductively coupled plasma-mass spectrometry. Analytica Chimica Acta, 583, 296-302.

Greaves M.J., Elderfield H. and Klinkhammer G.P. (1989)

Determination of the rare earth elements in natural waters by isotope-dilution massspectrometry. Analytica Chimica Acta, 218, 265-280.

Grinberg P., Willie S. and Sturgeon R.E. (2005)

Determination of $\mathrm{U}$, Th and $\mathrm{Pu}$ in natural waters, biological materials and clinical samples by ETV-ICP-MS. Journal of Analytical Atomic Spectrometry, 20, 717-723.

Jochum K.P., Nohl U., Herwig K., Lammel E., Stoll B., Hofmann A.W. (2005)

GeoReM: A new geochemical database for reference materials and isotopic standards. Geostandards and Geoanalytical Research, 29, 333-338.

Krachler M., Zheng J., Fisher D. and Shotyk W. (2004) 
Novel calibration procedure for improving trace element determinations in ice and water samples using ICP-SMS. Journal of Analytical Atomic Spectrometry, 19, 1017-1019.

\section{Lawrence M.G. and Kamber B.S. (2007)}

Rare earth element concentrations in the natural water reference materials (NRCC) NASS-5, CASS-4 and SLEW-3. Geostandards and Geoanalytical Research, 31, 95-103.

Lukman H., Akhmad S., Mitsuko O. and Shoji M. (2007)

Synthesis of novel Chitosan resin derivatized with serine diacetic acid moiety and its application to on-line collection/concentration of trace elements and their determination using inductively coupled plasma-atomic emission spectrometry. Analytica Chimica Acta, 588, 73-81.

\section{McKelvey B.A. and Orians K.J. (1998)}

The determination of dissolved zirconium and hafnium from seawater using isotope dilution inductively coupled plasma mass spectrometry. Marine Chemistry, 60, 245-255.

Möller P., Dulski P. and Luck J. (1992)

Determination of rare earth elements in seawater by inductively coupled plasma-mass spectrometry. Spectrochimica Acta Part B: Atomic Spectroscopy, 47, 1379-1387.

\section{Rahmi D., Zhu Y.B., Fujimori E., Umemura T. and Haraguchi H. (2007)}

Multielement determination of trace metals in seawater by ICP-MS with aid of down-sized chelating resin-packed minicolumn for preconcentration. Talanta, 72, 600-606.

Rodushkin I., Nordlund P., Engström E. and Baxter D.C. (2005)

Improved multi-elemental analyses by inductively coupled plasma-sector field mass spectrometry through methane addition to the plasma. Journal of Analytical Atomic Spectrometry, 20, 1250-1255.

Rodushkin I. and Ruth T. (1997)

Determination of trace metals in estuarine and sea-water reference materials by high resolution inductively coupled plasma mass spectrometry. Journal of Analytical Atomic Spectrometry, 12, 1181-1185. 
Shabani M.B., Akagi T., Shimizu H. and Masuda A. (1990)

Determination of trace lanthanides and yttrium in seawater by inductively coupled plasma mass-spectrometry after preconcentration with solvent extraction and back-extraction. Analytical Chemistry, 62, 2709-2714.

\section{Shaw T.J., Duncan T. and Schnetger B. (2003)}

A preconcentration/matrix reduction method for the analysis of rare earth elements in seawater and groundwaters by isotope dilution ICPMS. Analytical Chemistry, 75, 33963403.

Taylor S.R. and McCLennan S.M. (1985)

The Continental Crust: its Composition and Evolution. Blackwell Scientific Publications (Oxford), 312 pp.

Willie S.N. and Sturgeon R.E. (2001)

Determination of transition and rare earth elements in seawater by flow injection inductively coupled plasma time-of-flight mass spectrometry. Spectrochimica Acta Part B: Atomic Spectroscopy, 56, 1707-1716.

Wu J.F. and Boyle E.A. (1997)

Low blank preconcentration technique for the determination of lead, copper, and cadmium in small-volume seawater samples by isotope dilution ICPMS. Analytical Chemistry, 69, 24642470.

Yabutani T., Chiba K. and Haraguchi H. (2001)

Multielement determination of trace elements in seawater by inductively coupled plasma mass spectrometry after tandem preconcentration with cooperation of chelating resin adsorption and lanthanum coprecipitation. Bulletin of the Chemical Society of Japan, 74, 31-38.

Yeghicheyan D., Carignan J., Valladon M., Bouhnik Le Coz M., Le Cornec F., CastrecRouelle M., Robert M., Aquilina L., Aubry E., Churlaud C., Dia A., Deberdt S., Dupré 
B., Freydier R., Gruau G., Hénin O., de Kersabiec A.-M., Macé J., Marin L., Morin N., Petitjean P. and Serrat E. (2001)

A compilation of silicon and thirty one trace elements measured in the natural river water reference material SLRS-4 (NRC-CNRC). Geostandards Newsletter: The Journal of Geostandards and Geoanalysis, 25, 465-474.

\section{Zhu Y., Itoh A., Fujimori E., Umemura T. and Haraguchi H. (2005)}

Multielement determination of trace metals in seawater by inductively coupled plasma mass spectrometry after tandem preconcentration using a chelating resin. Bulletin of the Chemical Society of Japan, 78, 659-667.

\section{Figure captions}

Figure 1. Iron-coprecipitation experiments using Tm-doped ultra-diluted ( 2,500,000 times) solutions of the rock standard BIR-1. Results are expressed as the mean deviation of our measurements relative to the BIR-1 ultra-diluted solution. This graph gives information on the degree of co-precipitation efficiency for the elements determined. For example, a relative deviation of $-100 \%$ for any given element in this diagram would indicate that no scavenging occurred onto Fe-hydroxide phases during the experiment. The shaded areas represent the relative uncertainties in elemental concentrations of our BIR-1 diluted solution, calculated using the standard deviations given by Jochum et al. (2005) when available (see Table 2).

Figure 2. Post-Archean Australian Shales (PAAS)-normalized REE patterns for NRCC water reference materials. Normalization values are taken from Taylor and McCLennan (1985). Note that the Sm anomaly observed in each of the four CRM does not correspond to a natural oceanic feature, but reflects instead contamination during reference material preparation (e.g. Lawrence and Kamber, 2007). 
Table 1 .

ICP-MS operating conditions and measurement parameters

\begin{tabular}{ll}
\hline RF power & $1250 \mathrm{~W}$ \\
Sample uptake rate & $1 \mathrm{ml} / \mathrm{min}$ \\
Coolant argon flow rates & $16.11 \mathrm{l} / \mathrm{min}$ \\
Auxiliary argon flow rates & $0.61 \mathrm{l} / \mathrm{min}$ \\
Nebulizer argon flow rates & $0.88 \mathrm{l} / \mathrm{min}$ \\
Torch & quartz \\
Nebulizer & Teflon® $100 \mathrm{\mu l}$ \\
Spray chamber & Stable Sample Introduction (SSI) dual quartz chamber \\
Cones & Nickel \\
Low resolution mode (LRM) & ${ }^{89} \mathrm{Y},{ }^{90} \mathrm{Zr},{ }^{135} \mathrm{Ba},{ }^{139} \mathrm{La},{ }^{140} \mathrm{Ce},{ }^{141} \mathrm{Pr},{ }^{146} \mathrm{Nd},{ }^{147} \mathrm{Sm},{ }^{151} \mathrm{Eu}$ \\
& ${ }^{157} \mathrm{Gd},{ }^{159} \mathrm{~Tb},{ }^{163} \mathrm{Dy},{ }^{165} \mathrm{Ho},{ }^{167} \mathrm{Er},{ }^{174} \mathrm{Yb},{ }^{175} \mathrm{Lu},{ }^{178} \mathrm{Hf},{ }^{232} \mathrm{Th},{ }^{238} \mathrm{U}$ \\
Medium resolution mode (MRM) & ${ }^{45} \mathrm{Sc},{ }^{51} \mathrm{~V},{ }^{55} \mathrm{Mn},{ }^{60} \mathrm{Ni},{ }^{63} \mathrm{Cu}$ \\
Acquisition mode & $\mathrm{E}-\mathrm{scan}$ \\
No. of scans & $4(\mathrm{LRM})+4(\mathrm{MRM})$ \\
lon lens settings & Adjusted daily to obtain maximum signal intensity \\
Wash time & 3 min $(5 \%$ v/v HNO$)$ \\
\hline
\end{tabular}


Table 2.

Total procedural blank, blank contribution to studied reference materials and concentration values of BHVO-2 and BIR-1 used in this study

\begin{tabular}{|c|c|c|c|c|c|c|c|c|}
\hline \multirow{2}{*}{ Element } & \multirow{2}{*}{$\begin{array}{l}\text { Procedural } \\
\text { blank (pg) }\end{array}$} & \multicolumn{4}{|c|}{$\begin{array}{l}\text { Blank contribution to studied reference } \\
\text { materials (\%) }\end{array}$} & \multirow{2}{*}{$\begin{array}{c}\text { BHVO-2 } \\
\left(\mu \mathrm{g} \mathrm{g}^{-1}\right) \\
\text { (Barrat et al., } \\
2007) \\
\text { best estimate }\end{array}$} & \multirow{2}{*}{\multicolumn{2}{|c|}{$\begin{array}{c}\text { BIR-1 (s) } \\
\left(\mu g^{-1}\right) \\
\text { (Jochum et al., } \\
2005) \\
\text { preferred values }\end{array}$}} \\
\hline & & CASS-4 & SLEW-3 & NASS-5 & SLRS-4 & & & \\
\hline Y & 9 & 0.4 & 0.2 & 0.3 & 0.1 & 27.6 & 15.6 & $(0.9)$ \\
\hline $\mathrm{Zr}$ & 78 & 3 & 6 & 5 & 0.8 & 178 & 14 & $(0.1)$ \\
\hline $\mathrm{Ba}$ & 244 & 1.0 & 0.2 & 1.2 & - & 131 & 7.14 & \\
\hline La & 5.8 & 0.6 & 0.7 & 0.4 & 0.02 & 15.2 & 0.615 & (0.021) \\
\hline $\mathrm{Ce}$ & 7.3 & 1.9 & 1.1 & 1.3 & 0.02 & 37.5 & 1.92 & $(0.08)$ \\
\hline $\operatorname{Pr}$ & 0.8 & 0.6 & 0.5 & 0.4 & 0.01 & 5.31 & 0.37 & $(0.02)$ \\
\hline $\mathrm{Nd}$ & 3.4 & 0.6 & 0.4 & 0.4 & 0.01 & 24.5 & 2.38 & $(0.01)$ \\
\hline Sm & 0.6 & 0.1 & 0.1 & 0.1 & 0.01 & 6.07 & 1.12 & $(0.02)$ \\
\hline $\mathrm{Eu}$ & 0.4 & 1.8 & 0.7 & 1.2 & 0.04 & 2.07 & 0.53 & \\
\hline Gd & 1.0 & 0.8 & 0.3 & 0.5 & 0.03 & 6.24 & 1.87 & $(0.04)$ \\
\hline $\mathrm{Tb}$ & 0.2 & 0.9 & 0.4 & 0.6 & 0.04 & 0.94 & 0.36 & $(0.03)$ \\
\hline Dy & 0.4 & 0.3 & 0.1 & 0.2 & 0.02 & 5.31 & 2.51 & \\
\hline Ho & 0.2 & 0.6 & 0.2 & 0.4 & 0.04 & 1.00 & 0.56 & $(0.05)$ \\
\hline Er & 0.4 & 0.3 & 0.1 & 0.2 & 0.03 & 2.54 & 1.66 & \\
\hline $\mathrm{Tm}$ & 0.3 & 0.2 & 0.1 & 0.2 & 0.02 & 0.35 & 0.25 & $(0.03)$ \\
\hline $\mathrm{Yb}$ & 0.2 & 0.2 & 0.1 & 0.2 & 0.02 & 2.00 & 1.65 & \\
\hline Lu & 0.1 & 0.4 & 0.2 & 0.3 & 0.04 & 0.27 & 0.25 & $(0.02)$ \\
\hline $\mathrm{Hf}$ & 1.8 & 5 & 9 & 10 & 0.6 & 4.28 & 0.582 & (0.004) \\
\hline Th & 3.8 & 7 & 17 & 24 & 0.2 & 1.21 & 0.032 & (0.004) \\
\hline$U$ & 2.0 & 0.001 & 0.001 & 0.001 & 0.04 & 0.41 & 0.01 & (0.001) \\
\hline Sc & 6.2 & 58 & 10 & $>100$ & 0.6 & 32.3 & 43 & (2) \\
\hline V & 334 & 0.3 & 0.1 & 0.3 & 1.0 & 317 & 319 & (18) \\
\hline $\mathrm{Mn}$ & 11284 & 11 & 12 & 54 & - & 1290 & 1363 & \\
\hline $\mathrm{Ni}$ & 5250 & 25 & 8 & 32 & 14 & 121 & 166 & (7) \\
\hline $\mathrm{Cu}$ & 2350 & 10 & 3 & 28 & - & 123 & 119 & (8) \\
\hline
\end{tabular}

s: standard deviation. 
Table 3.

Trace element concentrations $\left(\mathrm{ng} \mathrm{I}^{-1}\right.$ ) for CASS-4 and NASS-5

\begin{tabular}{|c|c|c|c|c|c|c|c|c|c|c|c|}
\hline \multirow{3}{*}{$\begin{array}{l}\text { Sample } \\
\text { Reference } \\
\text { Element }\end{array}$} & \multicolumn{5}{|c|}{ CASS-4 } & \multicolumn{6}{|c|}{ NASS-5 } \\
\hline & \multicolumn{3}{|c|}{ Bayon et al. (This work) } & \multirow{2}{*}{$\begin{array}{c}\text { Lawrence } \\
\text { and } \\
\text { Kamber } \\
(2007)\end{array}$} & \multirow{2}{*}{$\begin{array}{l}\text { Zhu et } \\
\text { al. } \\
(2005)\end{array}$} & \multicolumn{3}{|c|}{ Bayon et al. (This work) } & \multirow{2}{*}{$\begin{array}{c}\text { Lawrence } \\
\text { and } \\
\text { Kamber } \\
(2007)\end{array}$} & \multirow{2}{*}{$\begin{array}{l}\text { Rahmi et } \\
\text { al. (2007) }\end{array}$} & \multirow{2}{*}{$\begin{array}{c}\text { Shaw et } \\
\text { al. } \\
(2003)\end{array}$} \\
\hline & $\begin{array}{l}\text { Mean } \\
(n=3)\end{array}$ & $\mathbf{s}$ & RSD & & & $\begin{array}{l}\text { Mean } \\
(n=5)\end{array}$ & $\mathbf{s}$ & RSD & & & \\
\hline $\mathrm{V}$ & 1280 & 19 & 0.7 & nd & 1010 & 1331 & 30 & 1.1 & $\mathrm{nd}$ & nd & nd \\
\hline Y & 21 & 0 & 0.5 & 21.7 & 21 & 26 & 1 & 1.4 & 22.5 & 20.7 & nd \\
\hline $\mathrm{Zr}$ & 25.3 & 0.4 & 0.9 & nd & nd & 15.4 & 0.9 & 2.9 & nd & nd & nd \\
\hline La & 9.3 & 0.2 & 0.8 & 9.5 & 8.7 & 13.0 & 0.4 & 1.4 & 12.4 & 11.8 & 12.1 \\
\hline $\mathrm{Ce}$ & 3.85 & 0.03 & 0.3 & 4.7 & 4.2 & 5.55 & 0.11 & 1.0 & 5.8 & 5.2 & 4.5 \\
\hline $\operatorname{Pr}$ & 1.311 & 0.005 & 0.2 & 1.43 & 1.34 & 2.11 & 0.05 & 1.3 & 2.13 & 1.84 & 2 \\
\hline $\mathrm{Nd}$ & 5.51 & 0.05 & 0.4 & 6.16 & 5.8 & 8.8 & 0.3 & 1.8 & 8.61 & 7.50 & 8.9 \\
\hline $\mathrm{Sm}$ & 5.73 & 0.04 & 0.3 & 5.85 & 5.4 & 4.84 & 0.11 & 1.1 & 4.84 & 4.50 & 4.5 \\
\hline $\mathrm{Eu}$ & 0.21 & 0.02 & 4.6 & 0.25 & 0.25 & 0.305 & 0.014 & 2.3 & 0.34 & 0.29 & 0.27 \\
\hline Gd & 1.34 & 0.06 & 2.4 & 1.37 & 1.5 & 1.90 & 0.07 & 1.8 & 1.87 & 1.59 & 1.6 \\
\hline $\mathrm{Tb}$ & 0.189 & 0.008 & 2.1 & 0.21 & 0.19 & 0.283 & 0.006 & 1.1 & 0.28 & 0.24 & 0.21 \\
\hline Dy & 1.39 & 0.04 & 1.4 & 1.52 & 1.20 & 1.93 & 0.07 & 1.9 & 1.86 & 1.8 & 1.78 \\
\hline Ho & 0.368 & 0.008 & 1.1 & 0.42 & 0.38 & 0.48 & 0.02 & 1.8 & 0.48 & 0.43 & 0.37 \\
\hline $\mathrm{Er}$ & 1.202 & 0.010 & 0.4 & 1.41 & 1.12 & 1.50 & 0.03 & 0.9 & 1.46 & 1.36 & 1.37 \\
\hline $\mathrm{Yb}$ & 1.15 & 0.02 & 0.7 & 1.46 & 1.3 & 1.30 & 0.03 & 1.3 & 1.32 & 1.13 & 1.2 \\
\hline Lu & 0.184 & 0.002 & 0.6 & 0.26 & 0.2 & 0.204 & 0.009 & 2.1 & 0.19 & 0.2 & 0.18 \\
\hline $\mathrm{Hf}$ & 0.35 & 0.03 & 3.7 & nd & nd & 0.17 & 0.02 & 7.1 & nd & nd & nd \\
\hline Th & 0.51 & 0.02 & 1.7 & nd & 0.46 & 0.17 & 0.02 & 7.1 & nd & nd & nd \\
\hline Sc & 0.08 & 0.06 & 37.6 & nd & $\mathrm{nd}$ & $<0$ & & & nd & nd & nd \\
\hline
\end{tabular}

$\mathrm{s}$ : precision expressed as 1 standard deviation of $\mathrm{n}$ replicate measurements 
Table 4

Trace element concentrations $\left(\mathrm{ng} \mathrm{l}^{-1}\right)$ for SLEW-3 and SLRS-4

\begin{tabular}{|c|c|c|c|c|c|c|c|c|c|}
\hline \multirow{3}{*}{$\begin{array}{l}\text { Sample } \\
\text { Reference } \\
\text { Element }\end{array}$} & \multicolumn{4}{|c|}{ SLEW-3 } & \multicolumn{5}{|c|}{ SLRS-4 } \\
\hline & \multicolumn{3}{|c|}{ Bayon et al. (This work) } & \multirow{2}{*}{$\begin{array}{c}\text { Lawrence } \\
\text { and } \\
\text { Kamber } \\
\text { (2007) }\end{array}$} & \multicolumn{3}{|c|}{ Bayon et al. (This work) } & \multirow{2}{*}{$\begin{array}{c}\text { Lawrence } \\
\text { and } \\
\text { Kamber } \\
\text { (2007) }\end{array}$} & \multirow{2}{*}{$\begin{array}{l}\text { Rodushkin } \\
\text { et al. (2005) }\end{array}$} \\
\hline & $\begin{array}{l}\text { Mean } \\
(n=3)\end{array}$ & $\mathbf{s}$ & RSD & & $\begin{array}{l}\text { Mean } \\
(n=3)\end{array}$ & $\mathbf{s}$ & RSD & & \\
\hline $\mathrm{V}$ & 2584 & 152 & 2.9 & $\mathrm{nd}$ & 346 & 20 & 2.8 & $\mathrm{nd}$ & nd \\
\hline $\mathrm{Y}$ & 42 & 3 & 4.2 & 39.5 & 149 & 6 & 1.9 & 138.2 & 142 \\
\hline $\mathrm{Zr}$ & 11 & 2 & 8.4 & nd & 93 & 3 & 1.6 & nd & 106 \\
\hline $\mathrm{La}$ & 7.7 & 0.4 & 2.5 & 8.0 & 282 & 11 & 2.0 & 295 & 292 \\
\hline $\mathrm{Ce}$ & 6.6 & 0.3 & 2.0 & 7.6 & 357 & 14 & 1.9 & 370 & 365 \\
\hline $\mathrm{Pr}$ & 1.64 & 0.08 & 2.3 & 1.73 & 70 & 2 & 1.5 & 72 & 70 \\
\hline $\mathrm{Nd}$ & 7.93 & 0.13 & 0.8 & 8.50 & 270 & 6 & 1.1 & 273 & 274 \\
\hline $\mathrm{Sm}$ & 7.2 & 0.3 & 1.9 & 7.1 & 57.9 & 1.3 & 1.1 & 58.1 & 53.9 \\
\hline $\mathrm{Eu}$ & 0.480 & 0.012 & 1.3 & 0.61 & 9.43 & 0.13 & 0.7 & 8.08 & 7.6 \\
\hline $\mathrm{Gd}$ & 3.1 & 0.2 & 3.3 & 3.11 & 33.8 & 2.2 & 3.2 & 35.1 & 33.2 \\
\hline $\mathrm{Tb}$ & 0.453 & 0.013 & 1.5 & 0.45 & 4.33 & 0.07 & 0.9 & 4.47 & 4 \\
\hline Dy & 3.38 & 0.09 & 1.3 & 3.38 & 24.2 & 1.4 & 2.8 & 23.7 & 22.9 \\
\hline $\mathrm{Ho}$ & 0.91 & 0.02 & 1.2 & 0.92 & 4.8 & 0.2 & 2.5 & 4.9 & 4.4 \\
\hline $\mathrm{Er}$ & 2.70 & 0.07 & 1.2 & 2.75 & 13.6 & 0.2 & 0.9 & 13.2 & 12.8 \\
\hline $\mathrm{Yb}$ & 1.849 & 0.002 & 0.1 & 2.07 & 12.6 & 0.3 & 1.1 & 12.1 & 11.4 \\
\hline $\mathrm{Lu}$ & 0.291 & 0.009 & 1.6 & 0.33 & 1.93 & 0.06 & 1.5 & 1.94 & 1.8 \\
\hline $\mathrm{Hf}$ & 0.19 & 0.02 & 5.2 & nd & 3.01 & 0.03 & 0.6 & nd & 3.3 \\
\hline Th & 0.22 & 0.01 & 2.1 & $\mathrm{nd}$ & 21.5 & 0.9 & 2.1 & nd & 17 \\
\hline $\mathrm{Sc}$ & 0.55 & 0.09 & 7.9 & $\mathrm{nd}$ & 11.1 & 0.9 & 4.3 & nd & 12 \\
\hline
\end{tabular}




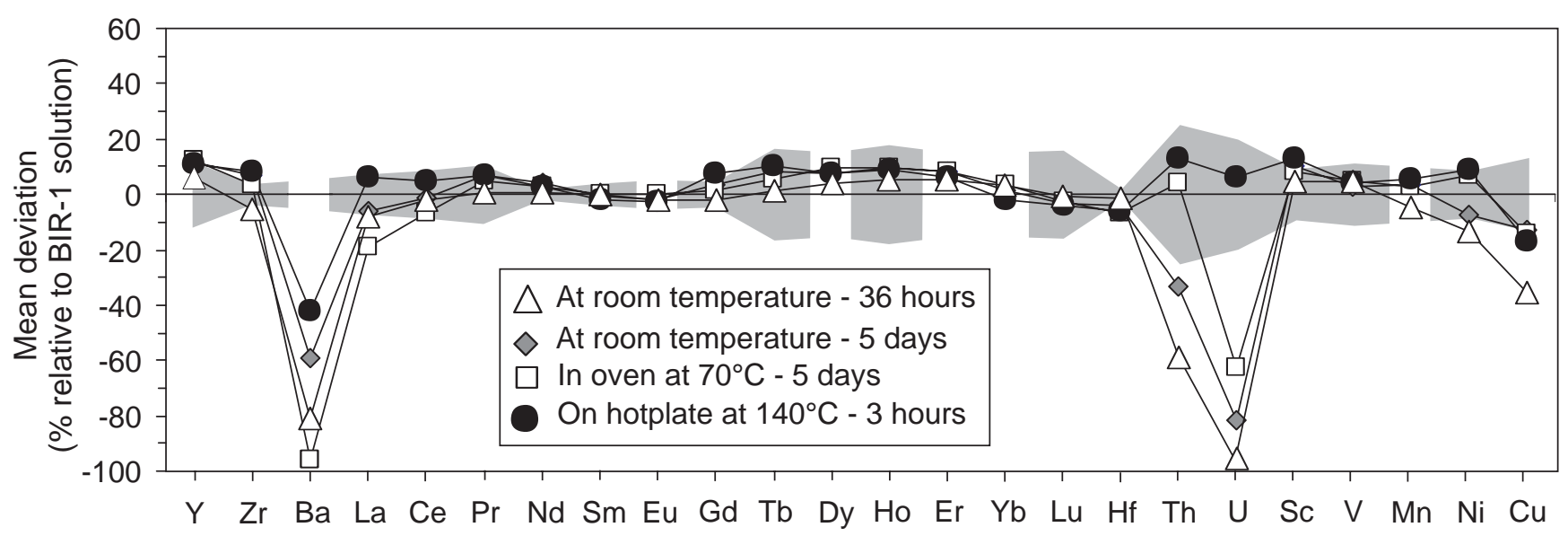

Fig1 

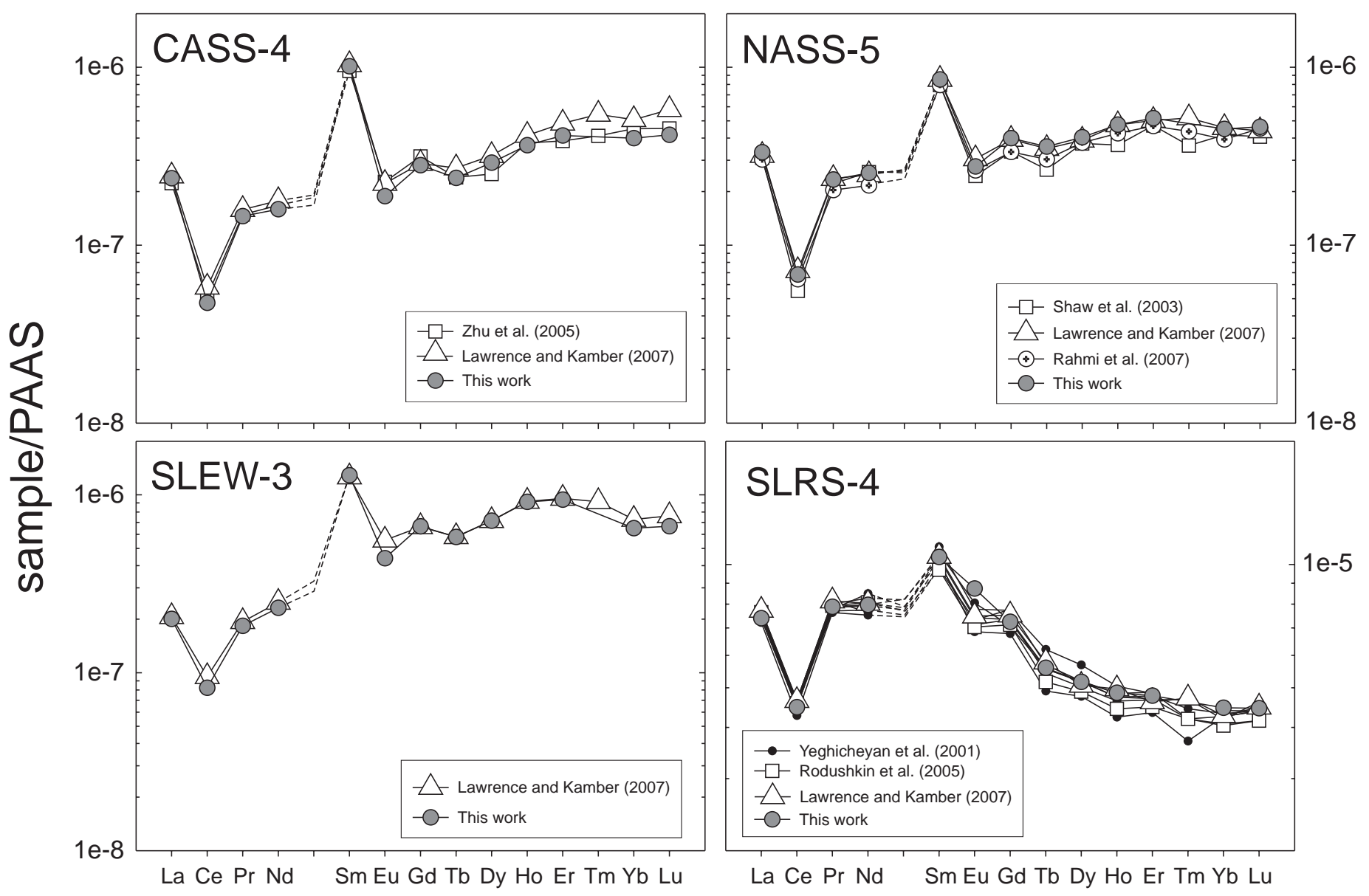

Fig2 